\title{
Application of Microlecture Combined with Flipped Classroom to the Teaching of Occupational Safety Protection for Probationer Nurses of Operating Room
}

\author{
Lian Huizhao", Qian Yuxiu", *, Guo Xiaoxia ${ }^{2}$, Hou Lihuan ${ }^{1}$, Gao Guie ${ }^{1}$, Xiao Xiaolu ${ }^{1}$ \\ ${ }^{1}$ Department of Operating Room, The First Affiliated Hospital of Jinan University, Guangzhou, China \\ ${ }^{2}$ The First Affiliated Hospital, Jinan University, Guangzhou, China
}

Email address:

gdqyx613@sina.com (Qian Yuxiu)

${ }^{*}$ Corresponding author

\section{To cite this article:}

Lian Huizhao, Qian Yuxiu, Guo Xiaoxia, Hou Lihuan, Gao Guie, Xiao Xiaolu. Application of Microlecture Combined with Flipped Classroom to the Teaching of Occupational Safety Protection for Probationer Nurses of Operating Room. Central African Journal of Public Health. Vol. 6, No. 3, 2020, pp. 131-135. doi: 10.11648/j.cajph.20200603.14

Received: March 1, 2020; Accepted: March 16, 2020; Published: April 8, 2020

\begin{abstract}
Objective: We attempt to explore the effect of microlecture combined with flipped classroom on the teaching of occupational safety protection for probationer nurses of operating room to figure out an effective teaching method to improve probationer nurses' occupational safety protection. Methods: We grouped probationer nurses who entered the department from March 2018 to March 2019. The first to fifth crews were grouped into the control group (61 nurses), and the sixth to tenth crews were grouped into the observation group (63 nurses). Theoretical assessment model: we tested the nurses using the same test paper at the first day they came to the department and the day before they left the department. Theoretical training model: at the end of the first week of practicing, the teaching group leader gave courses on occupational safety protection to the probationer nurses practicing in the operating room. The teaching method for control group was cramming intensive teaching mode while that for observation group was microlecture combined with flipped classroom in which problem-based group discussion was adopted. Two groups' satisfaction with the course design was investigated after class. At the fourth week prior to the end of the practicing, we assessed two groups' skill at conducting seven-step hand-washing method and dealing with sharp instrument injury and counted the occurrence of sharp instrument injury in probationer nurses. Results: Before training, there was no significant difference in the theoretical assessment results between control group and observation group $(P>0.05)$. After training, observation group had better results in theoretical assessment and skill operation than control group with a significant difference $(P<0.05)$. The occurrence of sharp instrument injury of the observation group was $7.9 \%(5 / 63)$ while that of the control group was $21.3 \%(13 / 61)$. There was a significant difference $(P=0.035)$. What's more, there was a significant difference in the satisfaction with course design between control group and observation group $\left(\chi^{2}=51.697, P=0.000\right)$. Conclusions: Microlecture in combination with flipped classroom is able to promote internalization and absorption of theoretical knowledge of occupational safety protection so as to improve probationer nurses' occupational safety protection knowledge and clinical skills. The teaching mode can also reduce the incidence of sharp instrument injury in probationer nurses and thus relieve probationer nurses' fear of occupational injuries during clinical practice. As a result, the probationer nurses are more active in the theoretical training. Therefore, microlecture combined with flipped classroom is effective on teaching the student nurses of the operating room the occupational safety protection knowledge.
\end{abstract}

Keywords: Microlecture, Flipped Classroom, Teaching, Probationer Nurse, Occupational Safety Protection

\section{Introduction}

Occupational exposure of medical staff occurs when they are exposed to any toxic or harmful substances or pathogenic microorganism during various medical or nursing care activities, which impairs their health and even life safety [1]. Working in the operating room renders the medical staff to be often exposed to patient's blood, body fluid and many other 
secreta as well as sharp instruments such as suture needle, scalpel and puncture needle, etc. which means that the operating room is a place with high occupational exposure [2-3]. Research [4] reports that the occurrence of occupational exposure in operating room nurses is $52.17 \%$ and in operating room probationer nurses is $44.71 \%$ [3]. Sharp instrument injury is the major occupational exposure. Probationer nurses have weaker operation skills and awareness of occupational safety protection due to lack of experience of clinical practice [5] and thus have high risk of occupational exposure. Some research [6-7] suggests that training on occupational protection for probationer nurses are effective to reduce occurrence of occupational exposure.

We taught theory and operation to the student nurses of operating room through microlecture and flipped classroom between 2018 and 2019 to instruct them in using occupational safety protection knowledge for self-protection and reduction of occupational exposure. Microlecture [8] is a teaching method, which delivers content through short video, online courses, related audio materials and many other multimedia materials. Flipped classroom [9] is also a teaching method, which requires students to prepare lessons before class through taking online courses, watching teaching videos, looking through related materials based on their own conditions so as to encourage students to raise questions and present what they have learned in class after independent study. Microlecture combined with flipped classroom provides resources for independent study and interaction allowing students to consolidate knowledge and strengthen memories using fragmentary time. This blending method can also promote informatization and optimization reform of teaching model. We applied microlecture combined with flipped classroom to the teaching of occupational safety protection knowledge for student nurses who entered the operating room between March 2018 and March 2019, which is reported as follows.

\section{Participants and Methods}

\subsection{Participants}

There were 10 crews of probationer nurses practicing in the operating room for 4 weeks from March 2018 to March 2019. The inclusion criteria are: (1) probationer nurses practicing in the operating room who volunteered to participate in this research, completed questionnaires by themselves and agreed to sign confidentiality agreements; (2) exclusion criteria: probationer nurses who refused to participate in the research or could not complete the questionnaires because of taking a vocation or quitting midway. We grouped the participants according to the time they entered the department. The first to fifth crew of probationer nurses were grouped into the control group (61 nurses) in which 52 were females and 9 were males with an average age of (21.49 \pm 0.96$)$, and 28 of them were undergraduates and 33 junior college students. The sixth to tenth crew of nurses were grouped into observation group (63 nurses) in which 49 were females and 14 were males with an average age of $(21.33 \pm 1.16)$, and 34 of them were undergraduates and 29 were junior college students. There was no significant difference in such general data as age, sex, education background and occupational safety KAP of the probationer nurses prior to practicing in the operating room between the two groups $P>0.05$ ).

\subsection{Methods}

\subsubsection{Teaching Methods}

The two groups of nurses would practice in the operating room for 4 weeks and one-on-one teaching of practice by mentor and intensive theoretical teaching by teaching group leader were adopted. The content of the intensive teaching and practice of the one-on-one teaching shared the same standard [10-11]. The content of the intensive teaching included sharp instrument injury, standard precautions, hand hygiene and occupational exposure, etc. Cramming theoretical teaching mode for the control group: at the end of the first week, the teaching group leader organized the probationer nurses to attend classes of 90 minutes namely 2 class hours, of which 40 minutes was used for theory about occupational safety protection, 15 minutes for teacher demonstration, 15 minutes for answering questions, discussion and summary, and 20 minutes for student practice. Microlecture combined with flipped classroom for the observation group: 1) we set up a WeChat group in which the teaching group leader explained the teaching purposes of microlecture and flipped classroom to the probationer nurses. The WeChat group included the nursing supervisor in charge of teaching, teaching group leader, clinical teachers, teaching secretary and the crew of probationer nurses. 2) reparation for the class: we recorded three 5-minute micro-videos about standard precautions, hand hygiene and treatment for sharp instrument injury respectively. Besides, PowerPoint courseware and instructions on procedures of dealing with occupational exposure were sent to the WeChat group for the probationer nurses preparing the lessons. We designed a quiz consisting of 15 questions on the operation and theory to test the nurses and the teaching group leader adjusted the teaching content according to the test results. The study task list was determined through question-based discussion and students were asked to group themselves in advance. Each crew composed of 12-14 people was divided into 3 groups each of which consisted of 4-5 people. 3 ) intensive teaching mode: the teaching took 2 class hours consisting of: (1) 10 minutes for analysis of the test results which focused on the mistakes, (2) 15 minutes for answering the questions in the study task list in three discussion groups, (3) 15 minutes for case analysis, (4) 20 minutes for operation skill drill of the students, including hand hygiene ( 5 minutes), standard precautions (5 minutes) and treatment for sharp instrument injury (10 minutes), (5) 30 minutes for teacher demonstration $(15$ minutes $)$ and answering questions, teasing out knowledge and summary (15 minutes). After class, questions were collected and sent to the WeChat group for students' continuous learning. The teaching group leader gave feedback on the existent problems to the clinical teachers to help them set clear teaching objectives. 


\subsubsection{Outcome Measurements}

(i). Results of Test for Theoretical Knowledge and Skill of Occupational Safety Protection before and after Teaching

Theoretical results: the teaching group leader used the same test paper to test the probationer nurses on their occupational safety protection knowledge at the first day they entered the department and the day before they left the department. The test paper was marked according to standard answers. Skill test results: at the end of the fourth week of practicing, the teaching group leader tested the probationer nurses on their performance of seven-step hand-washing method and treating sharp instrument injury. The results were given based on a uniform standard for evaluation.

(ii). Satisfaction with Course Design

The probationer nurses in two groups were asked to complete questionnaires on satisfaction with course design at the end of the theoretical training. Each nurse completed one questionnaire and submitted the questionnaire on the spot. There were 124 valid completed questionnaires and a questionnaire was composed of choices of very satisfied, basically satisfied and dissatisfied (the total satisfaction= (very satisfied + basically satisfied)/total cases).

(iii). Sharp Instrument Injury

At the end of the 4-week practicing, probationer nurses in both groups were asked to complete questionnaires on sharp instrument injury during practicing in the operating room. Each nurse completed one questionnaire which consisted of questions like whether having sharp instrument injury during practicing in the operating room. If the answer is "yes", tick the cause of the injury such as covering the cap of the needle, folding the ampoule, assisting the operation or disposing of the waste. The questionnaires were submitted on the spot and a total of 124 questionnaires were valid.

\subsection{Statistical Methods}

We adopted SPSS 17.0 to analyze data and $\bar{x} \pm s$ to describe measurement data. The independent-samples $\mathrm{T}$ test or rank sum test was used for comparison among groups. Comparison of enumeration data was done with chi-square test, and $\mathrm{P}<0.05$ indicates significant difference.

\section{Results}

\subsection{Comparison of the Results of Test on Occupational Safety Protection Knowledge Between Two Groups}

Test on knowledge of occupational safety protection included four models: sharp instrument injury (4 items, 4 points for each item with a total of 16 points), standard precautions (12 items, 3 points for each item with a total of 36 points), hand hygiene (6 items, 3-4 points for each item with a total of 19 points) and occupational exposure (8 items, 3-4 points for each item with a total of 29 points). There were 30 items with 100 points totally. Higher score meant that one mastered more correct knowledge of occupational safety protection. Before training, there was no significant difference in the score of test on theory of sharp instrument injury, standard precaution, hand hygiene and occupational exposure respectively and in total score between two groups $(P>0.05)$. After training, there was a significant difference in the score of test on the four models and total score between two groups $(P<0.05)$. The results are shown in the Table 1 .

Table 1. Comparison of Results of Test on Knowledge of Occupational Safety Protection between Two Groups.

\begin{tabular}{|c|c|c|c|c|c|c|c|c|c|c|c|}
\hline \multirow{2}{*}{ Groups } & \multirow{2}{*}{$\mathbf{n}$} & \multicolumn{2}{|c|}{$\begin{array}{l}\text { Sharp instrument } \\
\text { injury }\end{array}$} & \multicolumn{2}{|c|}{ Standard precautions } & \multicolumn{2}{|c|}{ Hand hygiene } & \multicolumn{2}{|c|}{ Occupational exposure } & \multicolumn{2}{|c|}{$\begin{array}{l}\text { Total score on } \\
\text { theoretical test }\end{array}$} \\
\hline & & $\begin{array}{l}\text { Before } \\
\text { training }\end{array}$ & $\begin{array}{l}\text { After } \\
\text { training }\end{array}$ & $\begin{array}{l}\text { Before } \\
\text { training }\end{array}$ & $\begin{array}{l}\text { After } \\
\text { training }\end{array}$ & $\begin{array}{l}\text { Before } \\
\text { training }\end{array}$ & $\begin{array}{l}\text { After } \\
\text { training }\end{array}$ & $\begin{array}{l}\text { Before } \\
\text { training }\end{array}$ & $\begin{array}{l}\text { After } \\
\text { training }\end{array}$ & $\begin{array}{l}\text { Before } \\
\text { training }\end{array}$ & $\begin{array}{l}\text { After } \\
\text { training }\end{array}$ \\
\hline $\begin{array}{l}\text { Observation } \\
\text { group }\end{array}$ & 63 & $6.73 \pm 4.48$ & $13.73 \pm 1.33$ & $30.60 \pm 1.98$ & $35.19 \pm 0.99$ & $17.11 \pm 1.06$ & $18.46 \pm 0.89$ & $17.71 \pm 1.67$ & $27.52 \pm 1.11$ & $68.92 \pm 7.53$ & $90.97 \pm 6.74$ \\
\hline Control group & 61 & $7.28 \pm 4.41$ & $9.27 \pm 1.95$ & $30.80 \pm 1.62$ & $32.27 \pm 1.84$ & $16.85 \pm 1.11$ & $17.98 \pm 1.11$ & $17.22 \pm 1.72$ & $25.13 \pm 1.80$ & $68.23 \pm 7.42$ & $78.86 \pm 6.22$ \\
\hline$Z / t$ & & 0.689 & -8.815 & -0.617 & 10.978 & 1.326 & 2.626 & 1.585 & 8.910 & 0.514 & 10.389 \\
\hline
\end{tabular}

\subsection{Comparison of Results of Test on Seven-step Hand-washing Method and Treatment for Sharp Instrument Injury After Training}

There was a significant difference in the test results of seven-step hand-washing method and treatment for sharp instrument injury between two groups $(P<0.05)$. Score of observation group was higher than that of control group, as shown in Table 2 .

Table 2. Comparison of Results of Test on Seven-step Hand-washing Method and Treatment for Sharp Instrument Injury between Two Groups ( $\bar{x} \pm \mathbf{S}$, score).

\begin{tabular}{llll}
\hline Groups & n & Seven-step hand-washing method & Treatment for sharp instrument injury \\
\hline Observation group & 63 & $97.06 \pm 2.29$ & $94.73 \pm 4.95$ \\
Control group & 61 & $77.74 \pm 18.62$ & $79.92 \pm 11.88$ \\
$t$ & & 8.045 & 9.009 \\
$P$ & & 0.000 & 0.000 \\
\hline
\end{tabular}

\subsection{Comparison of Occurrence of Sharp Instrument Injury During Practicing Between Two Groups}

The occurrence of sharp instrument injury of observation group was 7.9\% (5/63) and that of control group was $21.3 \%$ (13/61). Through analysis of chi-square test, there was a significant difference between the two groups $(P=0.035)$. 
Table 3. Comparison of Occurrence of Sharp Instrument Injury during Practicing between Two Groups (case).

\begin{tabular}{lllllll}
\hline Groups & $\mathbf{n}$ & Covering the cap of a needle & Folding the ampoule & Assisting operation & Disposing of the waste & Total \\
\hline Observation group & 63 & 2 & 1 & 2 & 0 & 5 \\
Control group & 61 & 3 & 2 & 6 & 2 & 13 \\
$\chi^{2}$ & & 0.243 & 0.376 & 0.376 & 2.099 & 4.468 \\
$P$ & & 0.622 & 0.540 & 0.226 & 0.147 & 0.035 \\
\hline
\end{tabular}

\subsection{Comparison of Satisfaction with Course Design on Occupational Safety Protection in Operating Room Between Two Groups}

There were 49 probationer nurses who were very satisfied with the course design in the observation group, accounting for $77.8 \%$, and 20 in the control group, accounting for $32.8 \%$. There was a significant difference in the total satisfaction between the two groups $\left(\chi^{2}=51.697, P=0.000\right)$, as shown in the Table 4 .

Table 4. Comparison of Satisfaction with Course Design on Occupational Safety Protection in Operating Room between Two Groups (case, \%).

\begin{tabular}{|c|c|c|c|c|c|}
\hline Groups & Cases & Very satisfied & Basically satisfied & Dissatisfied & Total satisfaction (\%) \\
\hline Observation group & 63 & $49(77.8)$ & $12(19.0)$ & $2(3.2)$ & $96.8 \%$ \\
\hline Control group & 61 & $20(32.8)$ & $19(31.1)$ & $22(36.1)$ & $63.9 \%$ \\
\hline$\chi^{2}$ & 51.697 & & & & \\
\hline$P$ & 0.000 & & & & \\
\hline
\end{tabular}

\section{Discussion}

\subsection{Analysis of the Status of Probationer Nurses' Knowledge of Occupational Protection}

Occupational protection refers to taking effective measures to avoid occupational injuries or reduce them to a minimum due to various occupational harmful factors that may cause body damage [12]. The level of occupational protection awareness is related to the cognitive level of knowledge. There are no special occupational protection courses for nursing students in school, so they cannot systematically acquire occupational protection knowledge. Moreover, the occupational protection knowledge they have learned is fragmented. Some of the knowledge is acquired from elective courses in infectious diseases, some from pre-clinical centralized training in hospitals, some from post-clinical practice under the guidance of clinical teacher, piecemeal education for admission navigation during rotation, and exchanges among students. The current study finds that the score of the test on occupational safety protection theory in the observation group is $(68.92 \pm 7.53)$ out of the total score of 100 , and in the control group it is $(68.23 \pm 7.42)$. Although there is no significant difference in the score between the two groups, it still indicates that lack of normative and systematic theory is the major cause of insufficient knowledge of occupational safety protection of nursing students.

\subsection{Employment of Flipped Classroom Teaching Mode to Motivate Probationer Nurse to Learn and Consolidate Knowledge of Occupational Safety Protection}

The flipped classroom [9] is a teaching method which asks students to learn before class, mainly through watching related online courses and teaching videos and looking through related materials on the online platform according to their own situation so that they can raise questions or demonstrate what they have learned in the class. The flipped classroom has overturned the traditional cramming teaching mode, and changed the learning state of the probationer nurses. Besides, the knowledge demonstration in the flipped classroom stimulates the probationer nurses to learn actively. After application of flipped classroom, out of the total score of 100 , the score of the test on occupational safety protection theory of the observation group is $(90.97 \pm 6.74)$ and that of the control group is $(78.86 \pm 6.22)$. There is a significant difference in the score between the two groups $(\mathrm{P}=0.000)$. Before training, the scores of treatment for sharp instrument injury of observation group and control group are $(6.73 \pm 4.48)$ and (7.28 \pm 4.41$)$ respectively; and the scores on occupational exposure theory of observation group and control group are (17.71 \pm 1.67$)$ and $(17.22 \pm 1.72)$ respectively. There is no significant difference in the score on theory between the two groups $(\mathrm{p}>0.05)$. However, after employment of flipped classroom for teaching of theory, comparison of scores on theoretical knowledge between observation group and control group is as follows: score on sharp instrument injury theory of observation group is $(13.73 \pm 1.33)$ and that of control group is (9.27 \pm 1.95$)$; scores on occupational exposure theory of observation group and control group are (27.52 \pm 1.11$)$ and $(25.13 \pm 1.80)$ respectively. There is a significant difference in the score on theory between the two groups $(\mathrm{P}=0.000)$. Therefore, the new teaching mode can inspire probationer nurses' learning potential, change their learning state from "negative" to "active" so as to promote internalization of knowledge and absorption, which helps to consolidate occupational safety protection knowledge and thus is favorable to occupational protection.

\subsection{Visual Education like Microlecture for Probationer Nurses to Learn More Frequently}

We recorded micro-lectures related to occupational safety protection in the operating room in advance. A total of 3 micro-videos about hand hygiene, standard precautions, treatment for sharp instrument injury were prepared and were used in the observation group. Two groups of probationer nurses were at the same time assessed on the performance of seven-step hand-washing method and treatment for sharp instrument injury at the end of the practicing in the operating room. Scores on performance of seven-step hand-washing method are (97.06 \pm 2.29$)$ 
and (77.74 \pm 18.62$)$ respectively in observation group and control group. There was a significant difference in the score on performance of seven-step hand-washing method between the two groups $(\mathrm{P}=0.000)$. Scores on the treatment for sharp instrument injury are $(94.73 \pm 4.95)$ and $(79.92 \pm 11.88)$ in the observation group and control group respectively. There was a significant difference in the score on treatment for sharp instrument injury between the two groups $(\mathrm{P}=0.000)$. As for the occurrence of sharp instrument injury, there are 5 cases in the observation group with an incidence of $7.9 \%$, and 13 cases in the control group with an incidence of $21.3 \%$. The occurrence in the observation group is lower than that in the control group with a significant difference $(\mathrm{P}=0.035)$. Some studies show that probationer nurses are lack of occupational safety protection knowledge, protection awareness and experience of performing protection operation [13]. Furthermore, some studies $[14,15]$ point out standardizing and proficient occupational safety protection operation helps reduce occupational exposure. Microlecture is a teaching method that teaches through a combination of short micro-videos, online courses, audio materials and many other multimedia materials. It can be used for group teaching or public welfare publicity, and also meet the needs of using fragmented time or optional projects to learn more frequently [8].

\section{Conclusions}

In summary, this study, through theoretical test on occupational safety protection knowledge of probationer nurses upon their entering the department, finds out the cause of their lack of occupational safety protection knowledge. We used flipped classroom for preparation of theoretical training and discussions for solving doubts. We also recorded micro-videos about occupational safety protection operations for occupational exposure that often occurs in the operating room, such as hand hygiene, standard precautions, and treatment for sharp instrument injury to standardize the nurses' performance of occupational safety protection operation. What's more, the dynamic and acoustic modes in micro-video can stimulate students' enthusiasm for learning, vibrating the boring classroom. Hence, probationer nurses can strengthen internalization and absorption of occupational safety protection knowledge so as to master correct occupational safety protection methods and reduce occupational injuries caused in clinical practice.

\section{References}

[1] Huiqiong, X., \& Xiaoping, P. (2010). Current situation investigation and countermeasure analysis of medical personnel's occupational protection. Modern Preventive Medicine, 37 (1): 29-31.

[2] Mohsen Adib-Hajbaghery, \& Mohammad Sajjad Lotfi. (2013).
Behavior of healthcare workers after injuries from sharp instruments. Trauma Monthly, 18 (2), 75-80.

[3] Ke-Ying, L., Wen, R., \& Yun, T.. (2013). Investigation and analysis of the current situation of pre-hospital first-aid nurses' occupational exposure and protection behaviors. Journal of Nursing Administration, 85 (8), 687-695.

[4] Choi, L. Y., Torres, R., Syed, S., Boyle, S., Ata, A., \& Beyer, T. D., et al. (2017). Sharps and needlestick injuries among medical students, surgical residents, faculty, and operating room staff at a single academic institution. Journal of Surgical Education, 74 (1), 131-136.

[5] Bajwa, J. S., Jaspal, S., \& Kaur, D.. (2014). Behavior, perception and compliance related to adoption of safety measures in response to needle stick injuries among nursing personnel at a tertiary care institute of north india. Journal of the Scientific Society, 6870 (1), 32-37.

[6] Jahangiri, M., Rostamabadi, A., Hoboubi, N., Tadayon, N., \& Soleimani, A.. (2016). Needle stick injuries and their related safety measures among nurses in a university hospital, shiraz, iran. Safety and Health at Work, 7 (1), 72-77.

[7] Garus-Pakowska, A., Mariusz Górajski, \& Szatko, F.. (2017). Did legal regulations change the reporting frequency of sharp injuries of medical personnel study from 36 hospitals in Łódź province, poland. International Journal of Occupational Medicine and Environmental Health, 31 (1): 37-46.

[8] Yichuan, Z., \& Yangyi, Q. (2013). The resource construction of microlecture at home and abroad and its latest application development. Journal of Distance Education, 31 (06): 26-33.

[9] Craig McBride. (2015). Flipping advice for beginners: what i learned flipping undergraduate mathematics and statistics classes. Primus, 25 (8), 694-712.

[10] Liwen, J., \& Bijie, H. Nosocomiology, Shanghai: Fudan University Press, 2012: 162-172.

[11] Xinjuan, Wu., \& Yanmei, Wang. Nursing Management, Beijing: People's Medical Publishing House, 2017: 235-236.

[12] Melek Serpil Talas. (2009). Occupational exposure to blood and body fluids among turkish nursing students during clinical practice training: frequency of needlestick/sharp injuries and hepatitis b immunisation. Journal of Clinical Nursing, 18 (10), 1394-1403.

[13] Rabaud, C., Agnès Zanea, Mur, J. M., Blech, M. F., Dazy, D., \& May, T., et al. (2000). Occupational exposure to blood: search for a relation between personality and behavior. Infection Control and Hospital Epidemiology, 21 (9), 564-574.

[14] Qing, G., Li-hong, L., Gui-qin, L., Fang-fang, L. (2019). Current situation and countermeasure on occupational protection for clinical postgraduates under the background of "clinical care-teaching collaboration". Chinese Hospitals, 23 (08): 33-36.

[15] Bin-Hua, L., Zhi-Yong, W. U., Fu-Tai, L. I., Li-Xia, C., Yan-Ru, S., \& Yu-Juan, L., et al. (2014). Investigation and analysis of the related risk factors of occupational exposure in medical staff. Chinese Journal of Nosocomiology, 24, 6223-6225. 